Boise State University

ScholarWorks

Marketing and Finance Faculty Publications and

Presentations

Department of Marketing and Finance

8-1-2008

\title{
An Introduction to the Special Issue on Marketing of High-Technology Products, Services and Innovations
}

Shikhar Sarin

Boise State University

Jakki Mohr

University of Montana - Missoula

\section{(1) $(1 \otimes \Theta$}

This is an author-produced, peer-reviewed version of this article. (C) 2009, Elsevier. Licensed under the Creative Commons AttributionNonCommercial-NoDerivatives 4.0 International License (https://creativecommons.org/licenses/by-nc-nd/4.0/). The final, definitive version of this document can be found online at Industrial Marketing Management, doi: 10.1016/j.indmarman.2008.04.011 


\title{
An Introduction to the Special Issue on Marketing of High-Technology Products, Services and Innovations
}

\author{
Shikhar Sarin \\ Kirk and Marsha Smith Professor of Marketing \\ College of Business and Economics \\ Boise State University \\ 1910 University Drive \\ Boise, ID 83725 \\ Phone: (208) 426-2721 \\ E-mail: ssarin@boisestate.edu \\ Jakki J. Mohr \\ Jeff and Martha Hamilton Distinguished Faculty Fellow \\ Professor of Marketing \\ School of Business Administration \\ University of Montana \\ Missoula, MT 59812 \\ Phone: (406) 243-2920 \\ E-mail: Jakki.mohr@business.umt.edu
}

We are pleased to introduce this special issue on marketing of high-technology products and innovations. High-technology industries are distinguished by increasing turbulence, and time- and information-intensive environments (Mohr, Sengupta and Slater 2009). Additionally issues related to unique characteristics like network effects, dominant design, and technological standards increase complexity in identifying, implementing, and evaluating marketing strategies in such environments (Hills and Sarin 2003). This special issue features papers that contribute theoretically, methodologically, and substantively to enhancing our understanding of marketing strategies in high-tech environments.

The articles in this special issue address a wide array macro- and micro-level issues ranging from:

- How do technologies evolve?

- Why do great firms fail?

- When should firms adopt an open system versus closed system architecture for new designs?

- How do knowledge networks evolve?

- To what extent is the conflict between marketers and engineers task-related vs. relational?

- How and why does the marketing function use influence strategies, such as upward appeal and coalition building, in high-tech firms? What are the consequences of such influence strategies?

In this introduction to the special issue, we overview the high points of the articles' contributions. In addition, we offer our own thoughts about future research on the topic of marketing of high-technology products and innovations. However, first and foremost we would like to acknowledge the important role of our special issue reviewers. A special issue is only as good as the manuscripts it receives, and the quality of the feedback provided by its reviewers. The reviewers of this special issue not only reviewed multiple versions of the manuscripts, but in some cases, reviewed multiple manuscripts or gave us a very rapid turnaround on reviews. We are enormously grateful to the reviewers whose names appear in the listing of special issue reviewers. We would also like to thank Peter LaPlaca, the editor of Industrial Marketing Management, for allowing us this opportunity to highlight an important and emerging stream of research in the marketing discipline. 


\section{Key Insights and Contributions from the Special Issue Articles}

In his opening commentary, Gerry Tellis, one of the most prolific and influential scholars in the area of technology and innovation, identifies ten big issues for marketing scholars to explore:

- How do technologies evolve?

- Why do great firms fail?

- Should firms make or buy innovations?

- What drives takeoff of innovations?

- What causes a trough in new product sales?

- Is network or quality more important for success of new innovations?

- Should hardware or software come first?

- Does innovation or advertising create great brands?

- What is the payoff to innovation?

- What drives the wealth of nations?

For each question, he provides a clear example, a succinct overview of existing theories in the area, and a clear articulation of why existing theories may not adequately address the question. We believe his essay will help crystallize many unanswered questions for readers in a concise, clear, and provocative manner.

In a similar vein, the second invited commentary, by Raji Srinivasan, offers a useful framework for examining the impact of emerging technologies in the high-tech environment. Many of you will recognize Raji for her excellent work on network externalities and dominant designs in high-tech markets.

Srinivasan's framework organizes the opportunities and threats from emerging technologies in terms of:

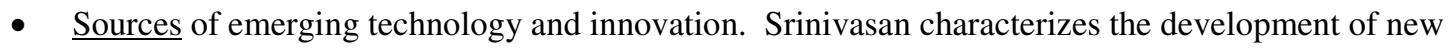
technologies as a "relay race" between small start-ups and established incumbents. Similarly, she describes the impact of new technologies as a "revolution by application;" in other words, when new technologies emerge, the particular market arena in which it will have its greatest impact is often unclear at first. The idea of a revolution by application implies that it may not be so much the technological innovation itself that creates industry disruption, but the application to which the innovation is put.

- $\quad$ Characteristics of emerging technologies. Clockspeed, or the pace of innovation, has implications for firms' decision making. For example, failure to respond to market changes in a fast-paced industry could result in technological lockout for a company. Digital convergence also can wreak havoc with existing company's product strategies and revenue models. The emergence of a dominant design in an emerging area, and its subsequent implications for firm strategy, as well as potential network effects are also technology characteristics she explores.

- Effects of emerging technologies. Srinivasan explores the notion of shifting value chains, in which technology undermines existing business models and sources of value; digitization of goods and its concomitant implications for pricing and customer adoption, and the shifting locus of innovation from R\&D labs inside the firm to user-led innovation and partnerships.

Srinivasan identifies a cornucopia of research opportunities for scholars to explore under each area. Astute readers will note some of the overlap between the issues in these two invited commentaries.

Bond, Houston and Tang examine combine both a macro level perspective (network) as well as micro-level perspective (firm-level), examining firms in Knowledge-Transfer-Networks (KTNs). KTNs are defined as networks of firms, government entities, research organizations, and industry trade associations that help to fund, develop and disseminate information and resources for new technologies. Many researchers (e.g., Mohr, Sengupta and Slater 2005; Hills and Sarin 2003) along with Tellis and Srinivasan note the increasing importance of networks in the success of high-tech products; however, much of this attention has focused on mature or established networks. In contrast, the paper by Bond, Houston and Tang examines the startup of KTNs. The authors draw upon social network theory, and attribution and motivation theories to explain key out comes (i.e., perceptions of knowledge transfer benefits from involvement in the 
knowledge-transfer network etc.) associated with the start-ups of a new KTN. Based on a case study of a British KTN, the authors find that early in the start-up stage of a KTN, identification by firms with the network not only affects the perceived knowledge transfer benefit a firm receives from the network, but also the perceived overall performance of the network. Moreover, Bond, Houston and Tang show that early in the start- up phase of a KTN, identification with the network and the perceived overall performance of the network are significantly related to continued commitment to the Knowledge-Transfer-Network.

Other competitive papers in the special issue offer a more micro perspective to marketing of high-tech products, focusing on issues internal to the high-tech company itself. Drawing upon attribution theory, Keaveney examines one of the most persistent issues in high-tech firms, the conflict between marketers and engineers. Much of the work on marketing-engineering conflict has focused on task-related conflict, overlooking the more enduring relationship-based conflict between the two functional areas. Keaveney adopts a qualitative approach, based on three data sets comprised of senior and mid-level engineers and marketing managers, to discover that marketers and engineers frequently ascribed personal attributions to their conflicts, which made it harder to resolve than task-based conflict. Moreover, she finds that the longer task-related conflict is allowed to persist, the more likely the conflict is attributed to personal reasons. Unlike Workman (1993), Keaveney finds evidence of increasing influence of the marketing function in high-tech firms. However she finds that the proportion of relationship-based conflict between marketing and engineering remains high.

Also taking a micro, firm-level approach, Atuahene-Gima and De Luca adopt a socio-political perspective to examine how the marketing function uses influence strategies to overcome its low formal power in the new product development context in high-tech firms. They survey $94 \mathrm{R} \& \mathrm{D}$ managers in Chinese high-tech firms and 122 R\&D managers in Australia. Their study speaks to the impact of power sources and the nature of $R \& D /$ marketing interaction on the types of influence strategies used, and the impact of those influence strategies on new product team understanding. Atuahene-Gima and De Luca find that the power of R\&D departments is positively related to marketing's use of lateral influence strategies (i.e., coalition building at the same level), as well upward appeals (i.e., seeking senior management intervention). While the use lateral influence strategies by marketing increases the understanding of marketing issues in hightech firms, the use of upward appeals seemed to have the opposite effect. Atuahene-Gima and De Luca also examine cross-national differences in the use of and response to influence strategies between Australian and Chinese firms. This cross-national comparison shows that while greater R\&D-marketing interaction increases the use of lateral influence strategies in Australian firms, it decreases the use of such strategies in Chinese firms, suggesting cultural differences in how functional areas engage in and respond to influence strategies.

While the invited commentaries in this special issue provide an overview of some of the broad themes in the marketing of high-tech products, services and innovations that will help guide the evolution of academic and managerial interests in this area, the empirical articles address some of the specific issues that will facilitate progress along these (and complementary) lines.

In the spirit of advocating for this evolving area within the marketing discipline, we offer three additional observations/suggestions that we hope scholars will use to help guide their efforts.

\section{Thoughts on Future Research on Marketing of High-Technology Products}

\section{Need for Mid-Level and Cross-Level Theories}

By and large, research on marketing of high-tech products has generally evolved around two different levels of analyses: the macro-level issues (i.e., industry change, dominant designs, product class sales, adoption and forecasting, etc.), and the micro-level issues (e.g., marketing's role in a high-tech firm, conflict between marketing and different functional areas within the firm etc., individual-level adoption behavior etc.).

Certainly, research at the macro level has been very successful at predicting product class, network, or industry level phenomena. Indeed, Tellis' opening commentary speaks eloquently to the issues in this 
stream of research. However, much like early diffusion research, many of these studies underplay the capabilities and constraints of organizations to influence their context. Because many macro-level studies do not account for specific organizational level variables, they are limited in the actionable guidelines for firms at the operational level. Incorporation of firm resources and capabilities like absorptive capacity, commercialization resources, and appropriability regimes can greatly enhance the actionable implications of these studies at the firm level (cf. Srinivasan, Lilien, and Rangaswamy 2006).

Micro-level studies, on the other hand, often fail to sufficiently acknowledge or incorporate the larger environmental and macro-forces affecting high-tech industries. Often, if they are included, these forces are used as covariates in model specification, controlling for confounding effects on the dependent variables.

House, Rousseau and Thomas-Hunt (1995) contend that limitations of purely micro and macro perspectives often lead to misspecified theories. Therefore, there is greater need for cross-level "Meso" theories that address two or more levels of analyses, combining macro- and micro-level variables, or both structural and behavioral variables (House, Rousseau and Thomas-Hunt 1995). The paper by Bond, Houston and Tang is an example of such an approach.

\section{Extending and Adapting Existing Theories to Account for High-Tech Characteristics}

In addition to extending the current micro- and macro-level perspectives as described above, research in marketing of high-tech products and innovations needs to move beyond simply applying existing concepts and theories to a high-tech context. Indeed, high-tech marketing cannot evolve as a separate area within the marketing discipline when "high tech" is simply used as a context for research.

Researchers must utilize the unique characteristics of the high-tech industries to extend existing marketing theories and concepts, find limitations and boundary conditions of existing theories, and propose new paradigms for research in this area. For example, Hills and Sarin (2003) argue that given the unique characteristics of high-tech markets, market driving would be an appropriate paradigm for marketing in the high-tech context, as opposed to being market driven. Similarly work by Tellis and colleagues (e.g., Sood and Tellis 2005; Stremersch, et al. 2007) have challenged conventional wisdom in disruptive technologies, product growth, and diffusion of innovations. Srinivasan, Lilien and Rangaswamy (2004) examined pioneering advantage under conditions subject to network effects. The need for insightful conceptual and empirical work in this area cannot be over-emphasized.

\section{Acceptance of a Broader Range of Methodological and Research Approaches}

A concern has grown in recent years that major marketing journals have become rather narrow in the range of methodologies and research approaches that are deemed "acceptable" (e.g., McAlister 2005; Rindfleisch, et al. 2008). Rather than allowing the methodological approaches to drive the agenda, research on marketing of high-tech products should focus on the substantive issues that need addressing, and then chose the methodology best suited to address the issue. Journals should be cognizant of the data constraints involved in addressing some problems related to marketing of high-tech products. For example, the paper by Bond, Houston and Tang examines the start-up phase of Knowledge-Transfer-Networks, and the authors note the paucity of networks in such a stage of their development. Similarly, building cross-level theories, which require both firm-specific and network level data, would place onerous data demands on the researchers. Under such circumstances, reliance on single methodological approaches even longitudinal ones like historical and archival data may not be sufficient. Therefore, journals must acknowledge that all methodological approaches come with their strengths and constraints, and they should be open to a wide variety of methodological approaches. Research problems, substantive issues and data constraints, should drive the choice of methodologies used, and not the other way around. Emphasis on rigor should not result in a pre-disposition to favor (or disfavor) one methodological approach over others. Articles in this issue address substantive problems using a variety of methodologies: qualitative (Keaveney), social network analysis (Bond, Houston and Tang), and surveys (Bond, Houston and Tang; Atuahene-Gima and De Luca). 


\section{Conclusion}

The set of papers in this special issue contributes insights to the field of high-tech marketing research, progressing towards our goal of stimulating rigorous theoretical, methodological, and substantive research in this arena. We hope you find the set of papers useful and invigorating to your own research and thinking. 


\section{$\underline{\text { References }}$}

House, Robert J., Denise M. Rousseau, and Melissa Thomas-Hunt (1995), "The Meso Paradigm: A Framework for the Integration of Micro and Macro Organizational Behavior," Research in Organizational Behavior, 17, 71-114.

McAlister, Leigh (2005), “Towards Insight and Relevance," Journal of Public Policy and Marketing, 24 (1), 131-132.

Mohr, Jakki, Sanjit Sengupta, and Stanley Slater (2009), Marketing of High-Tech Products and Innovations, (forthcoming), third edition, Upper Saddle River, NJ: Prentice Hall.

Hills, Stacey Barlow and Shikhar Sarin (2003), "From Market-Driven to Market-Driving: A New Paradigm for the Marketing of High-Tech Products and Innovations," The Journal of Marketing Theory and Practice, 11 (3), 13-24.

Rindfleisch, Aric, Alan J. Malter, Shanker Ganesan, Christine Moorman (2008), "Cross-Sectional Versus Longitudinal Survey Research: Concepts, Findings, and Guidelines," Journal of Marketing Research, (forthcoming).

Sood Ashish and Gerard J. Tellis (2005), “Technological Evolution and Radical Innovation?” Journal of Marketing, 69(3), 152-168.

Srinivasan, Raji, Gary L. Lilien, and Arvind Rangaswamy (2004), "First in, First out? Effect of Network Externalities on Pioneer Survival,” Journal of Marketing, 68 (1), 41-57.

Srinivasan, Raji, Gary Lilien, and Arvind Rangaswamy (2006), “The Emergence of Dominant Designs," Journal of Marketing, 70 (April), pp. 1-17.

Stremersch, Stefan, Gerard J. Tellis, Philip Hans Franses and Jeroen L. G. Binken (2007), "Indirect Network Effects in New Product Growth,” Journal of Marketing, 71(3), 52-74.

Workman, John (1993), "Marketing's Limited Role in New Product Development in One Computer Systems Firm," Journal of Marketing Research, 30(4), 405-421. 